\title{
The Greenway social housing estate: lessons in community development
}

\section{Commonwealth Journal of Local Governance}

Issue 19: December 2016

http://epress.lib.uts.edu.au/ojs/index.php/cjlg

\section{Chris Taylor}

The Big Issue

Bath

United Kingdom

\section{Jed Donoghue}

School of Social Sciences

University of Tasmania

Australia
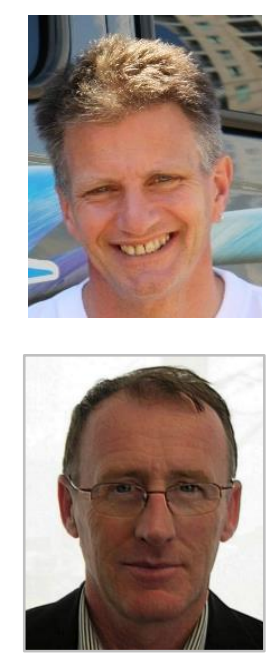

\begin{abstract}
Greenway is a self-contained estate for social housing tenants in the North Sydney local government area of Sydney, Australia. When Greenway opened in 1954 local newspapers reported on the modern, all electric units providing living opportunities for working people. By 2007 social isolation and antisocial behaviour at Greenway were regularly reported by the local press. The revitalisation of the Greenway estate occurred with the arrival of new residents who were keen to be actively involved in community development and stand for election to the Greenway Tenants Group (GTG). North Sydney Council supports the GTG with grants and expertise when required and also conducts elections on behalf of the tenants group.
\end{abstract}

\section{Introduction}

Greenway is a self-contained estate for social housing tenants in the North Sydney local government area of Sydney, Australia. The estate was built between 1948 to 1954 to house young workers and returned servicemen. Since its opening, Greenway has undergone many changes and challenges. In the last twenty years the estate has housed many older people with a variety of disabilities and health issues. It also has a significant population of people from Chinese speaking backgrounds. This paper

(C) 2016 Chris Taylor and Jed Donoghue. This is an Open Access article distributed under the terms of the Creative Commons Attribution 4.0 Unported (CC BY 4.0) License (https://creativecommons.org/licenses/by/4.0/), allowing third parties to copy and redistribute the material in any medium or format and to remix, transform, and build upon the material for any purpose, even commercially, provided the original work is properly cited and states its license. 
looks at the role of community development in working with the residents of Greenway and the local community over the last 20 years. In terms of community development practice we will provide a brief overview of some the programmes and partnerships that the Greenway community has been involved in between 1998 and 2015. We will also examine the ongoing issues for Greenway tenants and the outcomes that are yet to be achieved.

Greenway is situated next to the Sydney Harbour Bridge on former reclaimed land intended for the building of the Bridge access roads in the 1930s. It is well serviced by trains at the nearby Milsons Point station (Barrett 2004). The apartments were named after Australia's first architect, an ex-convict called Francis Greenway, who was sent out to Australia for committing forgery in England in 1814. Greenway was initially sentenced to death, but he had influential friends and his sentence was commuted. He was transported to Sydney Cove with a letter of introduction for Governor Macquarie (GTG 2015).

The building complex was the largest apartment development in the southern hemisphere at the time. The estate consists of four blocks, A, B, C and D containing 122, 22, 128 and 37 flats respectively. The smaller blocks became available for occupancy in late 1952, whilst blocks A and C were completed late 1953. The entire project took five years to complete. Greenway was officially opened on 28th March 1954 by descendants of Francis Greenway's family (GTG 2015).

\section{Defining community development}

While the purpose of this paper is not to provide a detailed definition of community development it is worth briefly mentioning a few of the different forms it has taken over the last 60 years. According to the Budapest Declaration (2004), community development is defined as a way to strengthen civil society by prioritising the actions of communities and their perspectives in the development of social, economic and environmental policy. Most importantly, community development seeks to empower local communities and seeks to strengthen the capacity of people to be active citizens through their community groups. Communities in this paper are defined as geographical, of common interest or identity. The Budapest Declaration (2004) focuses on disadvantaged communities, promoting core values such as social inclusion, equality and respect for diversity.

Community development can also be understood in an historical context. Community development practice can be traced back to the British Colonial office in the post Second World War period which placed an emphasis on literacy training, health and social services through local self-help (Colonial Office 1958). In the 1960s and 1970s collective action was promoted by community leaders taking a more political and direct action approach to improve their local and regional amenities and services. According to Henderson and Thomas (2012) during the 1980s community development practice became more focused on local organisations working together and creating support networks. 
In the last twenty years capacity building, community building and sense of place have become more popular concepts and practices. Capacity building allowed for both top-down and bottom-up approaches. In some instances it has been concerned with the delivery of services to a particular community and maintaining standards. In other cases it has been about transferring control of services, such as social housing or disability care, to the local community and developing services to meet local needs (NSWFoHA 2014).

The concept of social planning was introduced into community development departments in the 1990s (Henderson and Thomas 2012). This practice provided for the professional assessment of local needs and the setting of goals and priorities by consultants. In NSW local governments were required by the NSW Department of Local Government to undertake social planning and produce social plans. More recently community development concepts have merged with concepts of social sustainability. The Western Australian Council of Social Services define the principles of social sustainability as including equity, diversity, interconnectedness, quality of life, democracy and governance.

\section{Greenway population changes}

When Greenway opened in 1954 local newspapers reported on the modern, all-electric units, which provided living opportunities for working people. In the 1950s Greenway had a population of nearly 1,000 people. There was a live-in caretaker (Sun Herald 1953) and the allocation of housing places was determined by public lottery (Barrett 2004). In the intervening years Greenway has undergone many changes; the building of the 'freeway' resulted in the closure of many of the local facilities and the tram service also closed in 1958 (Barratt 2004).

Changes to the housing allocation system meant that people were prioritised for housing according to their health needs. The ageing of the local population has seen Greenway predominantly occupied by people aged 65 years of age or above. Many tenants have disabilities or are frail (Australian Bureau of Statistics 2011). The population changed again in the late 1980s with the implementation of the Richmond Report 1983, when a significant number of younger people recovering from mental illness were allocated housing in the Greenway estate. The report recommended that:

The Minister for Health should negotiate an arrangement with the Minister for Housing whereby a proportion of welfare housing stock in existing and proposed developments is specifically made available as hostel and group home accommodation for mentally ill people (Richmond 1983).

Over the last fifty years the size of Australian households has become much smaller according to the Australian Bureau of Statistics (ABS) census (2011). In the North Sydney Local Government Authority, the average house size was 2.2 people per household compared to 1954 when the average house size was over five people per household (ABS 2011). According to the NSW Dept. of Housing the official population of Greenway in 2014 was approximately 380 people, which is almost $60 \%$ lower than in 1954. 


\section{Tenants groups and North Sydney Council 1996-2000}

By the late 1990s the press and local community had turned against Greenway, reporting that the estate was responsible for most of the crime and anti-social behaviour in the area. At the same time service providers were reporting that the uptake of community services in Greenway was very low (North Sydney Council 2001). While there had been informal tenants groups at Greenway before (Barrett 2004), in 1998 two new tenants groups were formed, including people in different unit blocks who wanted to improve conditions and promote a more positive image of Greenway. One of the new tenant groups, the Greenway Tenants Group (GTG), reopened the community centre and started to provide information and assistance to tenants. The other group, the Greenway Tenants Association (GTA), folded when its leaders moved away from the area. To develop and sustain its activities the GTG made an approach to North Sydney Council for resourcing to advocate for tenants and improve conditions.

The response by North Sydney Council was to undertake a community needs assessment to build on the findings of a previous survey undertaken in 1993 by students. At the time it was felt that in order to improve the sense of community and quality of life on the estate it was important to establish what services were involved at Greenway and what tenant needs were unmet. The Council needs assessment found that there was not a great awareness of services or high level of community involvement at Greenway. The 2001 Action Plan contained a number of strategies that were focused on service delivery and service gaps. Improved access to public transport was identified as a basic need, as was the need for minor maintenance such as changing light globes (North Sydney Council 2001). In response the GTG put forward a proposal to set up an 'odd jobber's scheme' involving tenants, but this was not resourced or promoted due to lack of government funding. The lack of resources and promotion limited the capacity of the GTG to initiate positive change on the estate. However, the GTG continued to meet and develop relationships with the community workers at North Sydney Council, which demonstrated bottom-up capacity building.

\section{North Sydney Council interventions 2001-2004}

Between 2001 and 2004 a number of activities were supported and resourced by the local council including improvement to the local open spaces, an arts programme for the $50^{\text {th }}$ anniversary of the estate and a history research programme resulting in the publication of two books on Greenway. These activities were supported by council staff working at Greenway, who were directly involved in the planning of the $50^{\text {th }}$ anniversary celebrations. The planned community development process also involved identifying other agencies that could support, network with, and provide resources to the Greenway community. In the 12 months leading up to the Greenway anniversary in March 2004 a multi-agency organising committee met on a monthly basis to coordinate events and residents were encouraged to become involved in the planning and activities (Barrett 2004). 
The success of the Greenway $50^{\text {th }}$ anniversary celebrations led to greater engagement with the local tenants and created more interest in the provision of activities and programmes. The anniversary also helped to improve relationships with the wider community (North Sydney Council 2004). However, following the 50th anniversary celebration in March 2004 the increased resourcing and interest in the Greenway site slowly faded and most of the arts and social programmes were not sustained.

\section{North Sydney Council interventions 2005-2015}

By 2007 social isolation and anti-social behaviour at Greenway was again being reported by the local press and by community organisations. In response the local council convened a working party inviting all local community organisations known to be involved with Greenway for a series of meetings with the objective of forming a Greenway Action Plan. This was the beginning of what we would term organisational community development, which started to bring diverse agencies to work together for the common good. While the action plan was never fully endorsed by the committee, some ideas and actions were implemented between 2007 and 2010.

The Greenway Tenants Group received funding from the local council to open the community centre for three days a week using volunteers providing tenants with information and access to computers. At the same time some other residents started to develop the open space at the back of the apartments into small gardens; this is another example of 'bottom-up' capacity building by the local tenants. The local council negotiated with NSW Housing to lease the private Greenway Drive, in order to control and prohibit the consumption of alcohol and make it a private residents' car park. North Sydney Council and the tenants group also produced a new residents' advice package but this was never distributed.

By the time of the 2011 Census, it was evident that the population of Greenway was becoming older and frailer. There were demands for improved access to the apartments and local roads (GTG 2015). The growing population of Chinese speaking older residents at Greenway (Kirribilli) were not well engaged or accessing community care services for the elderly (ABS 2011). At the same time the tenants group was struggling to attract volunteers to open the community centre for three days a week. There was dissatisfaction with the tenants group which was perceived as exclusive and not acting in the interests of all tenants living at Greenway (GTG 2015). As a result the local council's resourcing of the group declined.

The revitalisation of the Greenway Tenants Group occurred with the arrival of new residents who were keen to be actively involved in community development and stood for election to the committee. Following a period of inactivity and the closure of the community rooms due to a lack of volunteers, the 2011 GTG committee elections ensured that all positions were contested. This resulted in a newlook tenants' committee made up of the new residents who were elected. There were a number of immediate actions by the new committee including information in Chinese, the community centre 
opening five days a week and a commitment to improving the look and image of the open space. The aim of the new tenants' committee was to encourage more people to come and join in the GTG activities. For the first time the GTG set and ran English language classes in the community centre for newly arrived residents.

North Sydney Council entered into discussions with the GTG in order to make the new programmes and committee more sustainable. Through networking with different government agencies, resources and grants were found and different ways of self-resourcing were implemented. For example, a $\$ 30,000$ grant to improve the public open space was received from the office of Family and Community Services (FACS). Assistance with rubbish removal, open space and weed removal was received from the North Sydney Council to improve the front and entrance gardens. A recycling market was held on a monthly basis to provide income. A local engineering company assisted with open space improvements and provided volunteers. With nearly 100 Chinese residents, information and the newsletters were printed in Mandarin for the first time in 2012. A twice-weekly food bank for residents was set up in partnership with OZHarvest, a food recycling social enterprise. At the time of writing the NSW Health Department and the Medicare local service centre are working with the GTG to provide a fully operational Health and Wellbeing centre for social housing tenants in the local area (GTG 2016). North Sydney council continues to support the GTG with small grants and expertise when required and also conducts the Annual General Meeting elections on behalf of the tenants group.

These actions included a number of spontaneous activities, for example, computers were donated to the Greenway Community Centre, which provides internet use, a range of art and language classes, haircuts, photocopying and newspapers. A community gardening project was also developed. The GTG promoted free and fair elections which were open to all Greenway tenants to promote greater interest in the activities and membership of the tenants group. A $60^{\text {th }}$ anniversary CD book was launched and improvements were made to the open spaces around the estate.

\section{Conclusions}

This brief overview of the community development work undertaken by North Sydney Council over the last 20 years highlights a number of important issues. While the interventions have taken many forms and have had different objectives, it is clear that establishing and maintaining good relationships with the tenants, community agencies and the local media is very important. Much of the work undertaken at Greenway was very dependent on there being an active and well-resourced tenants group. While North Sydney Council has supported the GTG it has done so in a reactive way. NSW Housing and the Council could have assisted the tenants group to develop a business plan, which included a commitment to free and fair elections in return for assistance with setting up and maintaining the estate office. The sustainability of the tenants group required the ongoing recruitment and training of volunteers as part of the community development and renewal process. 
This case study demonstrates that community development in social housing estates such as Greenway needs to involve local community agencies and businesses in a positive and proactive way. Community workers need to identify and recruit partner organisations that can provide additional support and resources to the tenants group. This would assist with the development and the sustainability of the tenants group. Good working relationships also need to be developed with local media agencies. Over the last two decades the majority of media coverage of the Greenway estate has been negative. Much of the negative media coverage could have been prevented, or at the very least balanced, by a wellplanned marketing strategy to promote all the positive activities and outcomes that have been achieved on the estate. Media training for the volunteers involved in the Greenway tenants group would also have been very useful and would have enabled and empowered them to counter the bad news stories and claims of anti-social behaviour on the estate.

\section{References}

Australian Bureau of Statistics. (ABS) (2011) Census North Sydney LGA. Canberra: ABS.

Barrett, G.W. (2004) Greenway the great survivor, fifty years in the life of a public housing estate. Sidney: North Sydney Council.

Colonial Office. (1958) Community development, a hand book. London: HMSO.

Combined European Bureau for Social Development. (2004) The Budapest Declaration. Building European civil society through community development. Available at: http://www.scdc.org.uk/media/resources/documents/budapestdeclaration4683d.pdf [Accessed December 2016].

Greenway Tenants Group. (GTG) (2015) History of Greenway. Available at: http://www.greenwaytg.com.au/history.html [Accessed 8 September 2015].

Greenway Tenants Group. (GTG) (2016) Greenway wellbeing centre. Available at: http://www.greenwaytg.com.au/wellbeing-centre.html [Accessed December 2016].

Henderson, P. and Thomas, D.N. (2012) Skills in neighbourhood work. (Third edition). London: Routledge.

North Sydney Council. (2001) Report into the needs of Greenway 2001. Sydney: NSC.

North Sydney Council. (2004) Report on the Greenway 50th anniversary. Sydney: NSC.

NSW Federation of Housing Associations. (2014) People and place management. Sydney: NSWFoHA.

Richmond, D.T. (Chairman of the Inquiry sponsored by the Department of Health, NSW) (1983) Inquiry into health services for the psychiatrically ill and developmentally disabled. New South Wales: Department of Health, NSW Division of Planning and Research.

The Sun Herald. (1953) 'This will do me', she says of her HC flat. $1^{\text {st }}$ March. 